\title{
The Research of Runoff Variation Characteristics of Wei River Basin LIU Junping ${ }^{1, a^{*}}$,WANG Wei ${ }^{1, b}, Z$ ZOU Junjie ${ }^{1, c}$, ZOU Xianbai ${ }^{1 . d}$
}

${ }^{1}$ Zhejiang University of Technology, College of Civil Engineering and Architecture, hangzhou, zhejiang, china

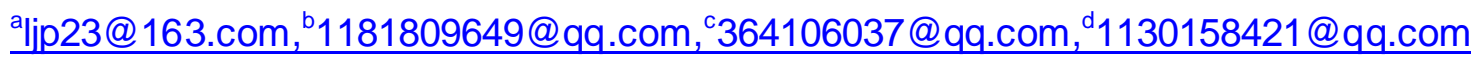

Keyword: Wei River; M-K mutation test method; runoff change; mutation characteristics Abstract: The research of basin runoff is one of the most important areas of research in surface water hydrology. This paper made an analysis of the runoff change trend and mutation characteristics of Wei River basin by the mathematical statistics of Kendall rank correlation coefficient and $\mathrm{M}-\mathrm{K}$ mutation test method with the annual and monthly runoff data of Hua Country hydrological station from 1960 to 2005. The result showed the runoff of Wei River basin had a trend of decline all four seasons and the change trend would remain in the future. The annual runoff mutation of Wei river basin occurred in 1981, the runoff mutation of spring occurred in 1966 and at the earliest time, the runoff mutations of summer and autumn respectively occurred in 1977 and 1985 , close to the annual runoff mutation time, the runoff mutation time of winter was uncertain. The precipitation didn't change too much before and after mutations, the mutations may be caused by human activities.

\section{Introduction}

Wei River, also known as Wei Water, the birthplace is bird and rat mountain in Gansu province. The tributaries of Wei River have Hulu River, Jing River and Luo River, etc. As the largest tributary of the Yellow River, the total length is $818 \mathrm{~km}$ and the basin area reach $1.34 \times 10^{5} \mathrm{~km}^{2}$. The landscape of Wei River basin is complex, the mountains include the north slope of Qinling mountain across Shanxi and Gansu province, Six Pan mountain and Long mountain, the fault basins include Guanzhong alluvial plain and loess platform. Wei River basin mostly is covered by deep loess, rich in calcium carbonate and vulnerable to erosion, the vegetation was destroyed by the long-term excessive reclamation in history and the single agricultural production mode led to serious water and soil loss, these made Wei River become a heavy sediment river. The water mainly came from the right blank branch and the sediment from the left. The climate belongs to continental climate, the annual averaged temperature is $6 \sim 13^{\circ} \mathrm{C}$ and the annual precipitation is about 500 800mm. More than 60\% occurred in 6 9 month, mainly for short-term heavy rain.

\section{The analysis method and data}

This paper made an analysis of the runoff change trend and mutation characteristics of Wei River basin by the mathematical statistics of Kendall rank correlation coefficient and M-K mutation test method with the annual and monthly runoff data of Hua Country hydrological station from 1960 to 
2005. In this paper, spring, summer, autumn and winter were divided to March to May, June to August, September to November, December to February of next year[1].

The change of climate is an important phenomenon generally existing in the climate system, which is a change of the climate transition from a relatively stable status to another status and a kind of performance of the nonlinear nature of climate system. The stable climate sequence ia as a prerequisite of $\mathrm{M}-\mathrm{K}$ mutation test. which is random independent and an equal probability distribution. The M-K method is described as follows [2,4].

Assuming the climate sequences are $x_{1}, x_{2}, \cdots, x_{n}$, the order list $S_{k}$ are the accumulative number of the $i$ sample $x_{i}$ greater than $x_{j}$. The computation formula is as follows

$S_{k}=\sum_{i=1}^{k} r_{i} \quad(2 \leq k \leq n)$

Among (1)

$r=\left\{\begin{array}{l}+1 \quad x_{i}>y_{i} \\ 0 \quad x_{i} \leq y_{i}\end{array} \quad(1 \leq j \leq i)\right.$

When $x_{1}, x_{2}, \cdots, x_{n}$ are independent of each other and with the same continuous distribution,

the mean value $E\left(S_{k}\right)$ and variance $\operatorname{Var}\left(S_{k}\right)$ of accumulative number $S_{k}$ can be calculated by the formula as follows

$$
\begin{aligned}
& E\left(S_{k}\right)=\frac{n(n-1)}{4} \\
& \operatorname{Var}\left(S_{k}\right)=\frac{n(n-1)(2 n-5)}{72}
\end{aligned}
$$

$S_{k}$ is standardized under the assumption of original sequence random independence

$U F_{k}=\frac{\left[S_{k}-E\left(S_{k}\right)\right]}{\sqrt{\operatorname{Var}\left(S_{k}\right)}} \quad(1 \leq k \leq n)$

The process above is repeated with the reverse column $x_{n}, x_{n-1}, \cdots, x_{1}$ of time series $x$, at the same time make

$U B_{k}=-\frac{\left[S_{k}-E\left(S_{k}\right)\right]}{\sqrt{\operatorname{Var}\left(S_{k}\right)}} \quad(1 \leq k \leq n)$

Where $k=n, n-1, \cdots, 1, U B_{1}=0$

The steps of M-K method are as follows:

(1) Computing the order $S_{k}$ of time sequence, and computing $U F_{k}$ by Eq. (5). 
(2) Computing the reverse order $S_{k}$ of time sequence, and computing $U B_{k}$ by Eq. (6).

(3) The significant horizontal line and the statistic curves of $U F_{k}$ and $U B_{k}$ are drawn on a graph under the premise of $g$ given significance level.

In the curve graph of $U F_{k}$ and $U B_{k}$, if $U F_{k}>0$ or $U B_{k}>0$, it shows the sequence is a trend of increase, if $U F_{k}<0$ or $U B_{k}<0$, it shows a trend of decrease. When the value of $U F_{k}$ and $U B_{k}$ are more than the reliability line, it shows sequence has an obvious trend of increase or decrease, the range above the reliability line is the time range occurring mutation, $U F_{k}$ raises over or falls below the critical value and the curve of $U F_{k}$ and $U B_{k}$ appear a intersection show the sequence occur mutation. The intersection of $U F_{k}$ and $U B_{k}$ is the beginning of mutation, $U F_{k}$ raises over the critical value shows the mutation from low to high, $U F_{k}$ falls below the critical value shows the mutation from high to low, if $U F_{k}$ and $U B_{k}$ have no intersection, the mutation can be considered to not happen[5,6].

\section{Analysis of characteristics of change}

\section{Analysis of runoff change trend}

The maximum annual runoff was $1.94 \times 10^{10} \mathrm{~m}^{3}$ and occurred in 1964 could be seen from fig. 1(a), The overall showed a decreasing trend and the decreasing rate was $1 \times 10^{6} \mathrm{~m}^{3} / 10 \mathrm{a}$. The fig.1(b) presented the runoff of four seasons in Hua country station also showed a decreasing trend and the decreasing rate respectively were: the rate of spring was $9.6 \times 10^{7} \mathrm{~m}^{3} / 10 \mathrm{a}$, summer was $3.36 \times 10^{7} \mathrm{~m}^{3} / 10 \mathrm{a}$, autumn was $1.8 \times 10^{8} \mathrm{~m}^{3} / 10 \mathrm{a}$, winter was $2.3 \times 10^{7} \mathrm{~m}^{3} / 10 \mathrm{a}$, the decreasing rate of autumn was the most obvious. The table 1 showed the Kendall rank correlation $M$ of spring and autumn were greater than the critical test value $M a=2.69(\alpha=0.01)$ [7], The $M$ of summer and autumn were less than Ma and decreased significantly. 


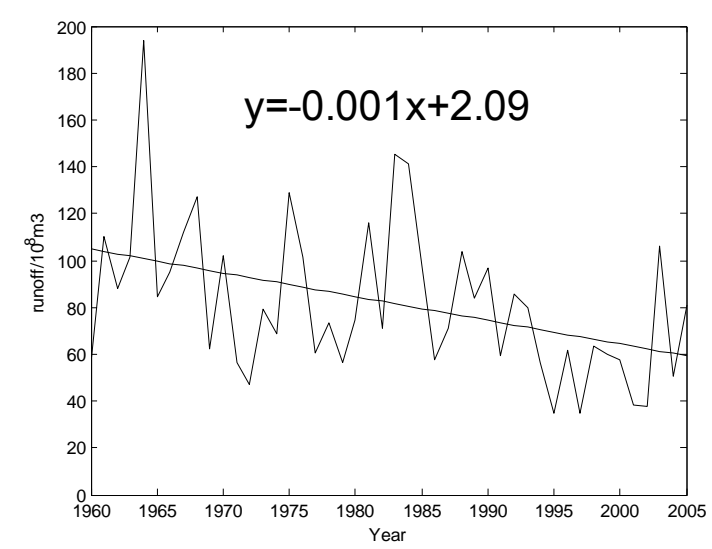

(a)Annual runoff change
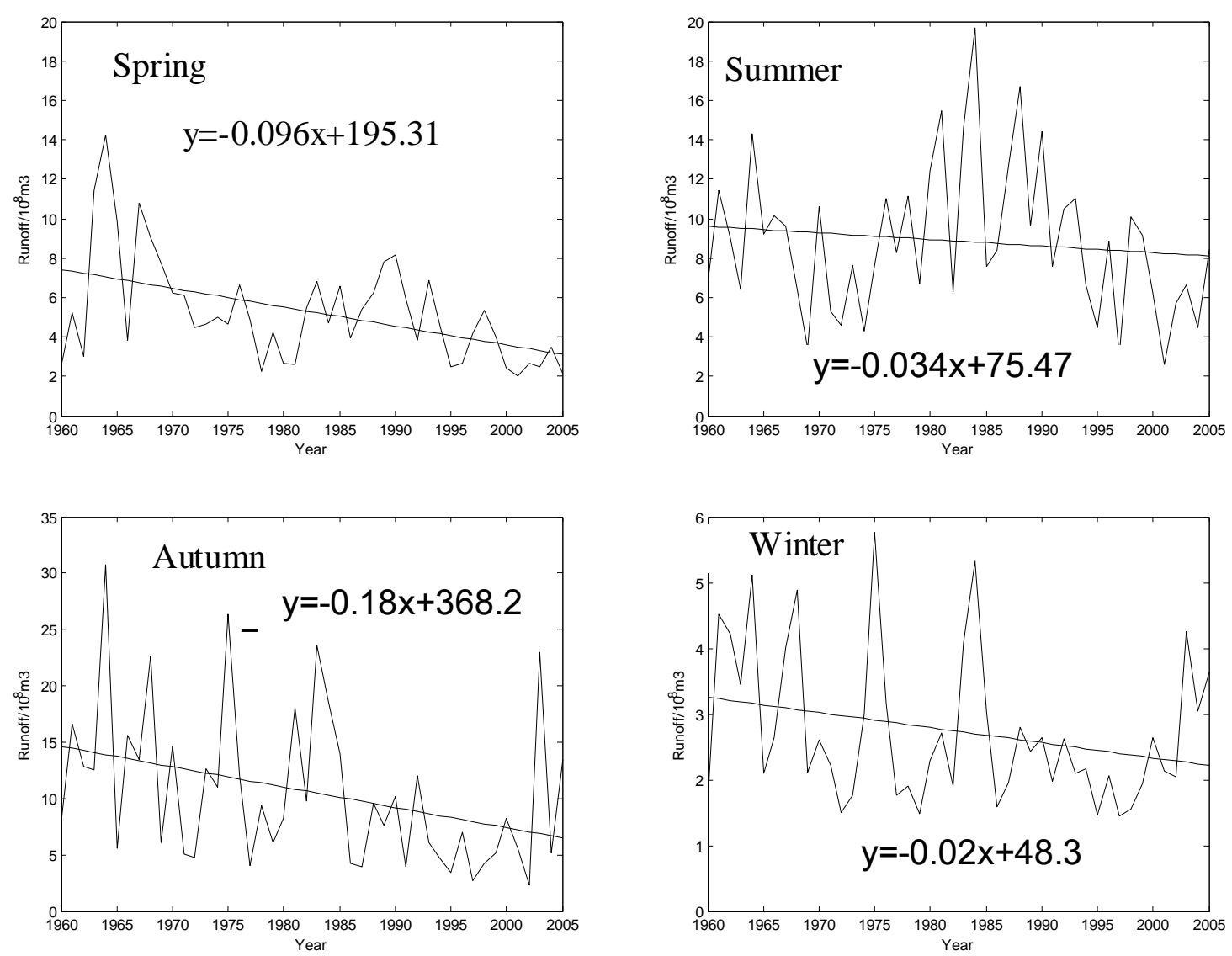

(b) Runoff change of four seasons

Table 1

Figure 1 Runoff change

Runoff change trend of four seasons

\begin{tabular}{c|c|c|c|c}
\hline Seasons & M & Trend & Ma & Significance \\
\hline Spring & -3.22 & Decline & 2.69 & significant \\
\hline Summer & -0.98 & Decline & 2.69 & non-significant \\
\hline Autumn & -2.89 & Decline & 2.69 & significant \\
\hline Winter & -1.38 & Decline & 2.69 & non-significant \\
\hline
\end{tabular}




\section{The analysis of runoff mutation point}

The mutation time of annual runoff and runoff of four seasons of Wei River can be shown on the $U F_{\mathrm{k}}-U B_{K}$ figure by the $\mathrm{M}-\mathrm{K}$ mutation test method[8,9]. The mutation of the annual runoff occurred in 1981, The mutation of spring occurred in 1966 and was the earliest, the summer was in 1977, the autumn was in 1985, the mutation time of winter was uncertain. The runoff mutation times of summer and autumn were most closely to the annual mutation time. The annual runoff was $9.08 \times 10^{9} \mathrm{~m}^{3} / \mathrm{a}$ before mutation and was $7.4 \times 10^{9} \mathrm{~m}^{3} / \mathrm{a}$ after mutation, which decreased $1.69 \times 10^{9} \mathrm{~m}^{3} / \mathrm{a}$. The runoff of summer and autumn respectively decreased $2.26 \times 10^{9} \mathrm{~m}^{3} / \mathrm{a}$ and $6.06 \times 10^{9} \mathrm{~m}^{3} / \mathrm{a}$, but the runoff of summer increased $1.19 \times 10^{9} \mathrm{~m}^{3} / \mathrm{a}$ after mutation, the runoff change of spring was most closely to annual runoff change, the runoff change of summer was the most obvious.

\section{Conclusions}

(1)This paper concluded the conclusions of the runoff decreasing rate of four seasons respectively were: the rate of spring was $9.6 \times 10^{7} \mathrm{~m}^{3} / 10 \mathrm{a}$, summer was $3.36 \times 10^{7} \mathrm{~m}^{3} / 10 \mathrm{a}$, autumn was $1.8 \times 10^{8} \mathrm{~m}^{3} / 10$ a, winter was $2.3 \times 10^{7} \mathrm{~m}^{3} / 10$ a, the decreasing rate of autumn was the most obvious. The table 1 showed the Kendall rank correlation $M$ of spring and autumn were greater than the critical test value $M a=2.69(\alpha=0.01)$, The $M$ of summer and autumn were less than $M a$ and decreased significantly.

(2)The mutation of the annual runoff occurred in 1981, The mutation of spring occurred in 191 and was the earliest, the summer was in 1977, the autumn was in 1985, the mutation time of winter was uncertain. The runoff mutation times of summer and autumn were most closely to the annual mutation time. It concluded the runoff changes of summer and autumn were the most contribution to the annual annual runoff change[10,11].

\section{Acknowledgements}

This work was financially supported by the Natural Science Foundation of Zhejiang Province (LY14E090007) and the Open Foundation of the Most Important Subjects of Zhejiang University of Technology(20150306).

\section{References}

[1] F.A.Abdulla, D.P.Lettenmaier , Development of regional parameter estimation equations for a macroscale hydrologic model, J.Hydrol.197 .230-257.

[2] Z.L.Wang, X.H.Chen, Y.Tao, The analys is of runoff change and impact factor of Dongjiang River basin about nearly 50 years,Journal of natural resources.25(8),1196-1374(2010).

[3] S.Yue, C.Y.Wang, A study of variability of annual river flow of the southern African region, Hydrolog Sci. 47(6),983-987(2002). 
[4] H.Chen, S.L.Guo, C.Y.Xu, Histrorical temporal trends of hydro-climatic variables and runoff response to climate variability and their relevance in water resource management in the Hanjoamg basin, Journal of Hydrology, 344,171-184 (2007).

[5] F.L.Ge, The causes of water quantity decrease in Weihe River and analyzing the variety of precipitation and runoff in south of Qinlin mountains, Journal of Northwest Hydroelectric Power, 20(1), 146-149(2004).

[6] S.Y.Liu, Y.Zhang, Y.S.Zhang, et al. Estimation of glacier runoff and future trends in the Yangtze River source region, Journal of Glaciology, 55, 353-362(2009).

[7] Z.S.Chen, Y.N.Chen, C.C.Xu, Change trend and prediction of annual runoff in mainstream area of the Tarim River in rencent 50 years, Arid Land Geography. 34(1),43-51(2011).

[8] J.Q.Li, Y.N.Chen, W.H.Li, Variation features of precipitation and runoff of the middle-small rivers of northern piedmont of Tianshan Mountains: a case of jinghe river, Arid Land Geography. 33(4),615-622(2010).

[9] R.E.Schulze, Modelling hydrological responses to land use and climate change: A southern African perspective, Ambio. 29(1),13-17.

[10] P.X.Liu, Study on the trend and period characteristics of climate change in the Minqin Oasis since recent 54 years, Arid Zone Research. 2009(7),471-476.

[11] T.D.Han, B.S.Ye, Y.J.Ding, Study on the change of streamflow in the upper reaches of the Yellow River in recent 40 years, Arid Land Geography. 27(4),553-557(2004). 